\title{
Role of extended release quetiapine in the management of bipolar disorders
}

REVIEW

This article was published in the following Dove Press journal:

Neuropsychiatric Disease and Treatment

13 February 2010

Number of times this article has been viewed

\author{
Rayan K Al Jurdi ${ }^{1,2}$ \\ Lena A Dixit' \\ Martha Sajatovic ${ }^{3}$ \\ 'Baylor College of Medicine, \\ Department of Psychiatry, Houston, \\ Texas, USA; ${ }^{2}$ South Central Mental \\ Illness Research and Clinical Core, \\ Department of Veterans Affairs, \\ Houston, Texas; ${ }^{3}$ Department of \\ Psychiatry, Case Western Reserve \\ University School of Medicine, \\ Cleveland, Ohio, USA
}

\begin{abstract}
Atypical antipsychotics have become a widely utilized component of the bipolar disorder treatment armamentarium, with approximately $45 \%$ of bipolar patients prescribed atypicals. Over the last decade all atypical drugs except for clozapine have received a Food and Drug Administration (FDA) bipolar indication. In October 2008, the FDA approved quetiapine XR monotherapy for the treatment of acute depressive episodes of bipolar disorder and acute manic or mixed episodes in bipolar I disorder based on two placebo-control trials. Quetiapine was also approved as adjunct therapy with lithium and divalproex for the treatment of acute manic or mixed episodes as well as maintenance of bipolar I disorder. In contrast to immediate release quetiapine which may require a twice-daily regimen, the XR formulation is intended for once-daily administration. This drug profile of quetiapine XR will address chemistry, pharmacodynamics, pharmacokinetics, metabolism, safety and tolerability and clinical trials in bipolar disorder.
\end{abstract}

Keywords: quetiapine XR, bipolar disorder

\section{Introduction}

Bipolar disorder is a life-long clinical illness characterized by the presence of cycling episodes of mania or hypomania and mostly episodes of depression. Men and women are equally affected across all ethnicities with an overall lifetime prevalence of about $2 \%-3 \%$.

Treatment of bipolar disorder must also address: 1) acute intervention for manic or depressive episodes, 2) maintaining long term remission and 3) prevention of recurrence. However, a major challenge has been that different medications may have limited therapeutic benefit for the disorder's polarity of symptoms or only have specific efficacy in certain phases of the illness. Moreover, medications may treat acute symptoms but not necessarily offer long-term maintenance.

Lithium has been used since the 1960s, often as first-line treatment for bipolar disorder. ${ }^{2}$ Major drawbacks to lithium include a narrow therapeutic window, a fairly long onset of action (1 to 3 weeks), and some may develop a tolerance over time.,

In the mid 1990s, the US Food and Drug Administration (FDA) approved the anticonvulsant valproate for the treatment of bipolar disorder. ${ }^{5,6}$ Other FDA-approved anticonvulsants for bipolar disorder include lamotrigine for bipolar maintenance and carbamazepine for acute mania. ${ }^{7,8}$ Typical antipsychotic drugs such as haloperidol and chlorpromazine are also used in the treatment of patients with bipolar disorder although side effects such as extrapyramidal symptoms (EPS) and tardive dyskinesia may limit their use.
Michael DeBakey VAMC, 2002 Holcombe

Blvd., MHCL II6, Houston,

TX, 77030, USA

Tel + I 7I3-794-8709

Fax + I 7|3-794-8I72

Email rayana@bcm.tmc.edu,

rayan.aljurdi@med.va.gov 
Atypical antipsychotics have become a widely used for the treatment of bipolar disorder. Using data from the Veterans Affairs National Psychosis Registry, Sajatovic and colleagues reported that $45 \%$ of subjects with bipolar disorder were on antipsychotics ( $n=73,964)$ as monotherapy or combination therpay. ${ }^{9}$ The great majority of individuals prescribed antipsychotic agents received atypical compounds ( $n=25,559,94.7 \%)$. The progressive increase in utilization of atypical antipsychotics in bipolar disorder is well documented. Depp and colleagues reviewed data of Medicaid beneficiaries with bipolar disorder receiving services in the San Diego County public mental health system. ${ }^{10} \mathrm{~A}$ total of 1473 clients were identified and trends of medications prescription were reviewed from 2001 to 2004. The percentage of subjects prescribed mood stabilizers or antipsychotics increased significantly, from $71 \%$ in 2001 to $77 \%$ in 2004 $(P<0.001)$. Interestingly, the percentage of subjects on mood stabilizers alone decreased from $25 \%$ to $20 \%(P=0.001)$, while the use of antipsychotics alone increased from $32 \%$ to $36 \%(P=0.008)$.

Over the last decade all atypical drugs except for clozapine have received Food and Drug Administration (FDA) bipolar indication. Side effect concerns with the atypical agents primarily involve abnormalities in metabolic functioning including medication-related diabetes as well as weight gain.

Both treatment efficacy and treatment-related adverse effects of different medication classes vary substantially between individual patients. For example, it is not possible to predict which individuals will go on to develop EPS from antipsychotic drugs, although risk is higher in general with high-potency typical compounds, high-doses and long-term use. Similarly, current technologies do not permit prediction of which individuals will experience the rare but serious side effect of Stevens-Johnson Syndrome that can occur with lamotrigine therapy, although risk is elevated in situations where dosing titration is rapid. Additionally across all bipolar medication pharmacotherapies rates of partial and full treatment nonadherence are in the order 50\%, indicating a need for treatments that are better accepted by patients. ${ }^{10}$

Newer formulations of currently approved bipolar medication treatments, such as extended-release formulations, orally dissolving tablets and injectable medications, may offer an opportunity to minimize side effects or improve patient acceptance or adherence. An extended-release (XR) formulation of quetiapine has recently been approved in the treatment of bipolar disorder and is intended to be administered as a once-daily dosing. However, it is not clear if a reduced dosing frequency will translate into greater acceptability or long-term adherence by patients with bipolar illness. This manuscript will examine the drug profile of quetiapine XR by addressing chemistry, pharmacodynamics, pharmacokinetics, metabolism, safety and tolerability, and clinical trials in bipolar disorder.

\section{Introduction to the compound}

Quetiapine XR is an atypical antipsychotic, belonging to what is generally referred to as second generation antipsychotics. Its active metabolite is N-desalkylquetiapine (norquetiapine). Quetiapine XR was approved in the United States in 2007 for the acute treatment as well for maintenance therapy of schizophrenia in adult patients. In October 2008, it gained FDA approval as monotherapy for treatment for bipolar disorder-acute depressive episodes, and bipolar I disorder-acute manic or mixed episodes. It also has FDA approval as adjunct therapy with lithium or divalproex for bipolar I disorder acute manic or mixed episode and maintenance. ${ }^{11}$ Quetiapine XR is available in $50 \mathrm{mg}, 150 \mathrm{mg}, 200 \mathrm{mg}, 300 \mathrm{mg}$ and $400 \mathrm{mg}$ prolonged release tablets.

\section{Chemistry of quetiapine $\mathbf{X} \mathbf{R}$}

Quetiapine extended release is a dibenzothiazinepine antipsychotic. The chemical designation is 2-[2-4-dibenzo[b,f] [1,4] thiazepin-11-yl-piperzinyl)ethoxy]-ethanol fumarate (2:1). Its molecular formula is $\mathrm{C}_{42} \mathrm{H}_{50} \mathrm{~N}_{6} \mathrm{O}_{4} \mathrm{~S}_{2} \cdot \mathrm{C}_{4} \mathrm{~h}_{4} \mathrm{O}_{4}$ and it has a molecular weight of $883.11 .{ }^{11}$

\section{Pharmacodynamics and mechanism of action}

Quetiapine has an affinity for multiple receptors most notably dopamine and serotonin. The reported dissociation constant values (Ki) are 428 and $626 \mathrm{nmol} / \mathrm{L}$ for $\mathrm{D}_{1}$ and $\mathrm{D}_{2}$ receptors; and 1040 and $38 \mathrm{nmol} / \mathrm{L}$ for $5-\mathrm{HT}_{1 \mathrm{~A}}$ and 5-HT ${ }_{2 \mathrm{~A}}$ receptors. ${ }^{11}$ Quetiapine displays affinity for $\alpha_{1 \mathrm{~b}}$ and $\alpha_{2 b}$-adrenoceptors (Ki 14.6 and $617 \mathrm{nmol} / \mathrm{L}$ ), histamine $\mathrm{H}_{1}$ receptors ( $\mathrm{Ki} 4.41 \mathrm{nmol} / \mathrm{L}$ ) but lacks significant affinity for muscarinic cholinergic $\left(\mathrm{M}_{1}\right)(\mathrm{Ki} 1086 \mathrm{nmol} / \mathrm{L})$ or benzodiazepines receptors $(\mathrm{Ki}>10000 \mathrm{nmol} / \mathrm{L}) .{ }^{12}$

Norquetiapine differs from quetiapine in having a higher affinity for serotonin $\mathrm{M} 1$ receptors (Ki $38.3 \mathrm{nmol} / \mathrm{L}$ ), $5 \mathrm{HT}_{2 \mathrm{~A}}$ (Ki $2.9 \mathrm{nmol} / \mathrm{L}), 5 \mathrm{HT}_{1 \mathrm{~A}}(\mathrm{Ki} 45 \mathrm{nmol} / \mathrm{L})$ and norepinephrine neurotransporter $(\mathrm{Ki} 12 \mathrm{nmol} / \mathrm{l}){ }^{13}$

The mood-stabilizing effects of quetiapine and quetiapine XR in bipolar disorder are believed to be mediated mostly through combined effect $\mathrm{D} 2$ and $5-\mathrm{HT}_{2 \mathrm{~A}}$ receptor antagonism. The mechanism effect on bipolar depression is 
less understood. The norepinephrine reuptake inhibition by norquetiapine has been suggested as a possible mechanism. Increased endogenous that have been related to depression. Quetiapine antihistaminic effect has been reported to indirectly down regulate endogenous cytokines such as interleukine $1 \mathrm{~b}$ and interleukine- 6 and thus can partly explain quetiapine XR effect on bipolar depression and mixed phases. ${ }^{14,15}$

\section{Pharmacokinetics and metabolism}

Quetiapine XR is well absorbed. Plasma concentration of quetiapine and norquetiapine are proportionate to the total daily dose. Peak plasma concentration of quetiapine XR is often reached in 6 hours, with a mean terminal half-life of 7 hours. At therapeutic levels, quetiapine has a volume of distribution of $10 \mathrm{~L} / \mathrm{kg}$ with $83 \%$ plasma protein binding. Absorption of quetiapine XR is highly affected by food intake. It is reported that a meal with high fat content can increase quetiapine $\mathrm{XR} \mathrm{C}_{\max }$ from $44 \%$ to $52 \%$ and $\mathrm{AUC}$ from $20 \%$ to $22 \%$ for the $50 \mathrm{mg}$ and $300 \mathrm{mg}$ tablets, respectively. Steady state concentrations are expected within 2 days of dosing. ${ }^{11}$

Quetiapine XR is metabolized by the liver. The primary pathways are via sulfoxidation and oxidation. In vitro studies report involvement of the cytochrome P450 3A4 isoenzyme. Using radiolabeled 14C-quetiapine, studies showed that $73 \%$ of the dose is recovered in urine and $20 \%$ from stools. Less than $1 \%$ of quetiapine XR is excreted unchanged. ${ }^{11}$

The quetiapine XR manufacturers' prescribing information reflects no need for dose adjustment in patients with decreased renal functions. A report of 8 subjects with severe renal insufficiency showed a $25 \%$ decrease in medication clearance compared to controls. ${ }^{16}$ However, the quetiapine $\mathrm{XR}$ dose continued to be within normal concentration range. However, the Electronic Medicine Compendium calls for using quetiapine $\mathrm{XR}$ with caution in patient with renal insufficiency. ${ }^{17}$

Dosage adjustments are recommended for patients with hepatic insufficiency. ${ }^{11}$ Liver functions deficiencies can significantly increase AUC and $\mathrm{C}_{\max }$ to up to 3 times compared to those seen in healthy subjects. Accordingly, medication dosage adjustment is highly recommended in this subpopulation.

Figueroa and colleagues ${ }^{18}$ compared pharmacokinetic profiles of quetiapine XR and quetiapine immediate release (IR) in patients with schizophrenia, and schizoaffective and bipolar disorder. In this open-label, randomized, crossover trial, all 28 subjects received quetiapine IR $150 \mathrm{mg} \mathrm{mg}$ twice a day and quetiapine XR $300 \mathrm{mg}$ daily over 4-day treatment intervals. Over a 24-hour dosing interval, $\mathrm{C}_{\max }$ of quetiapine XR was $13 \%$ less than quetiapine IR (495.3 vs $568.1 \mathrm{ng} / \mathrm{ml}, 90 \%$ confidence interval [CI] 0.77 to 0.99 ). $\mathrm{C}_{\mathrm{amx}}$ was achieved in 5 hours with quetiapine XR compared to 2 hours with quetiapine IR. Morning trough quetiapine concentrations $\left(\mathrm{C}_{\min }\right)$ showed no difference between the $\mathrm{XR}$ and IR formulations with $95.3 \mathrm{ng} / \mathrm{mL}$ and $96.5 \mathrm{ng} / \mathrm{mL}$, respectively, (90\% CI 0.77 to 1.31 ).

With similar AUC and oral clearance for both formulations of quetiapine, drug-drug interaction data of quetiapine XR can be extrapolated from the quetiapine IR studies. ${ }^{18}$ Quetiapine IR has a limited inhibitory effect on cytochrome P450 enzymes 1A2, 2DC, 2C19, 2D6 and 3A4 substrates. ${ }^{11}$ Its plasma concentration and clearance is affected by cytochrome 3A4 inhibitors and inducers. For example, ketoconazole slows quetiapine metabolism and thus increase its plasma concentration while phenytoin, carbamazepine and thioridazine lower it. ${ }^{17}$

\section{Clinical efficacy}

As monotherapy, the FDA-approved quetiapine XR for the treatment of acute depressive episodes of bipolar disorder and acute manic or mixed episodes in bipolar I disorder based on two placebo-control trials (see Table 1). The FDA has also approved it as adjunct therapy with lithium and divalproex for the treatment of acute manic or mixed episodes as well as maintenance of bipolar I disorder, though this latter approval appears to be based on extrapolated data from quetiapine IR studies. ${ }^{11}$

\section{Monotherapy treatment for acute mania/ mixed episodes}

The FDA approval of quetiapine XR for acute mania/mixed episode was based on a study by Cutler and colleagues. ${ }^{19}$ This randomized, multicenter, double-blind, parallel-group, placebo-controlled study included a total of 308 subjects with bipolar I with or without history of rapid cycling who were in acute manic or mixed episodes. Subjects recruited were 18 to 65 years of age with a Young Mania Rating Scale (YMRS) of $\geq 20$, and Clinical Global Impression-Bipolar-Severity of Illness (CGI-BP-S) overall score of $\geq 4$. All subjects were hospitalized for at least 4 days at the beginning of the study. One hundred and forty-nine subjects were randomized to receive quetiapine XR initiated at $300 \mathrm{mg}$ at the first day and increased to $600 \mathrm{mg}$ the following day. The target flexible daily dose ranged from 400 to $600 \mathrm{mg}$. The primary outcome measure was change of YMRS total score after 
Table I Summary of quetiapine XR acute mania and acute bipolar depression studies

\begin{tabular}{|c|c|c|}
\hline & Quetiapine XR for acute mania & Quetiapine XR for acute bipolar depression \\
\hline Author & Cutler $A$, et al ${ }^{19}$ & Suppes $T$ et $\mathrm{a}^{20}$ \\
\hline Design & $\begin{array}{l}\text { Randomized, parallel-group, double-blind, } \\
\text { placebo-controlled }\end{array}$ & $\begin{array}{l}\text { Randomized, parallel group double-blind, } \\
\text { placebo controlled }\end{array}$ \\
\hline Sample size & Quetiapine $X R=149$, placebo arm $=159$ & Quetiapine $X R=140$, placebo $=140$ \\
\hline Duration & 3 weeks & 8 weeks \\
\hline Mean daily dosage (range) & 604 mg (400-800 mg) & $300 \mathrm{mg}$ \\
\hline Primary outcomes & $\begin{array}{l}\text { Subjects on quetiapine XR showed a statistically } \\
\text { significant decline in total YMRS scores compared } \\
\text { to placebo }(-14.34 \text { vs }-10.52, P<0.00 \text { I })\end{array}$ & $\begin{array}{l}\text { Subjects on quetiapine XR showed a statistically } \\
\text { significant decline in total MADRS scores } \\
\text { compared to placebo }(-17.4 \text { vs }-11.9, P<0.00 \text { I). }\end{array}$ \\
\hline Reported side effects & $\begin{array}{l}\text { Sedation (34.4\%), dry mouth ( } 33.8 \%) \text {, somnolence } \\
(16.6 \%) \text {, headaches (I I.9\%), constipation }(9.9 \%) \text {, } \\
\text { dizziness }(9.9 \%) \text {, dyspepsia }(6.6 \%) \text {, fatigue } \\
(6.6 \%) \text { and weight gain }(6.6 \%)\end{array}$ & $\begin{array}{l}\text { Dry month ( } 37.2 \%) \text {, somnolence }(29.2 \%) \text {, sedation } \\
(23.4 \%) \text {, dizziness ( } 13.1 \%) \text {, increased appetite }(12 \%) \text {, } \\
\text { headache }(9.5 \%) \text {, constipation }(8.0 \%) \text {, nausea }(7.3 \%) \text {, } \\
\text { weight gain }(7.3 \%) \text {, dyspepsia }(6.6 \%) \text {, fatigue }(5.8 \%)\end{array}$ \\
\hline
\end{tabular}

Abbreviations: YMRS, Young Mania Rating Scale; CGI-BP-S, Clinical Global Impression-Bipolar-Severity of Illness; CGI-BP-C, Clinical Global Impression-Bipolar-change; MADRS, Montgomery-Åsberg Depression Rating Scale; AE, adverse events; EPS, extrapyramidal symptoms.

3 weeks of randomization. Secondary outcomes included YMRS remission rate (YMRS $<12$ ), response rate $(\geq 50 \%$ reduction in YMRS score) as well as changes in CGI-BP-S and CGI-BP-change (CGI-BP-C).

At the end of the study, subjects on quetiapine XR showed a statistically significant decline in total YMRS scores compared to placebo ( $-14.34 \mathrm{vs}-10.52, P<0.001)$. Among subjects on quetiapine XR, $55.0 \%$ showed response and $41.6 \%$ remission compared to only $33.3 \%$ and $27.7 \%$ on placebo $(P<0.001$ and $P=0.006)$.

\section{Monotherapy treatment for acute depressive episodes}

Suppes and colleagues have published data supporting the indication of quetiapine XR for the acute treatment of depression of bipolar I or II. ${ }^{20}$

Two hundred and eighty subjects were recruited in this study. They were aged 18 to 65 years of age with a Hamilton Depression Rating Scale-17 (HAMD-17) of at least 20 and YMRS of less than 12. Subjects were randomized to either placebo or quetiapine $\mathrm{XR}$ with the later being progressively tapered to a total of $300 \mathrm{mg}$ daily by day 4 of the study.

Changes in Montgomery-Åsberg Depression Rating Scale (MADRS) scores from baseline to end of the study was the primary outcome measure, while response (MADRS $\geq$ reduction in MADRS scores), remission (MADRS > 12), CGI-BP-S and CGI-BP-C were considered as secondary outcomes. By the end of the study, subjects on quetiapine XR showed on average a 17.4 point drop on total MADRS scores compared to 11.9 for those receiving placebo $(P<0.001)$. The separation between the two arms was evident as early as week one of randomization. Response was achieved by $65 \%$ of patients on active medication compared to $43.1 \%$ on placebo $(P<0.001)$. Similarly, more subjects on quetiapine XR achieved remission than placebo (54.1\% vs $39.4 \% ; P=0.018$ ). A mean decrease in CGI- BP-S of 1.82 was reported among the quetiapine XR arm compared to 1.25 in the placebo arm $(P<0.001)$. Finally, $63.2 \%$ of subjects receiving quetiapine XR reported "much improved" or "very much improved" by the end of the study on CGI-BP-C, compared to $39.4 \%$ receiving placebo.

\section{Safety and tolerability Common adverse events}

Available data from the two placebo-controlled trials provide information on adverse events that may be expected when quetiapine $\mathrm{XR}$ is prescribed to patients with bipolar disorder. ${ }^{17,18}$ These side effects were observed at a mean daily dose of quetiapine XR of $604 \mathrm{mg}$ (range 400 to $800 \mathrm{mg}$ ) over 3-week period for the mania study, and a fixed daily dose of $300 \mathrm{mg}$ over 8 weeks for the acute depression study.

Discontinuation rates were comparable to placebo though nearly a third of subjects receiving active medication withdrew from both studies. In the acute mania study, 44 participants $(\mathrm{n}=151)$ receiving quetiapine $\mathrm{XR}$ did not complete the study protocol: 12 lost to follow up, 13 voluntary termination, 6 lack of response, 3 worsening of condition and only 4 for adverse events. ${ }^{19}$ In comparison, 45 subjects in the placebo arm $(n=161)$ had an early termination with 15 reporting lack of response, 12 adverse events, and 12 voluntary discontinuation. 
In the acute bipolar depression study, Suppes et al reported an early termination of $37 \%$ in the active arm $(n=140)$ and $30 \%$ in the placebo arm $(n=140) .{ }^{20}$ Most common reasons for discontinuation in the quetiapine XR cohort were adverse events, lost to follow up and voluntary discontinuation in 17, 12 and 12 cases respectively. Lack of therapeutic response and voluntary discontinuation were the most common reasons for early termination in the placebo cohort with 10 cases each, followed by 8 lost to follow up and adverse events cited as a reason in only 2 cases.

During the 8-week acute depression study, the most commonly reported side effects were dry mouth (37.2\%), sedation $(23.4 \%)$, somnolence $(29.2 \%)$, increase appetite $(12.4 \%)$, headache $(9.5 \%)$ constipation $(8 \%)$, nausea (7.3\%), weight gain $(7.3 \%)$, dyspepsia $(6.6 \%)$ and fatigue $(5.8 \%) .{ }^{20}$ Similarly, sedation (34.4\%), dry mouth (33.8\%), somnolence $(16.5 \%)$ and headache $(11.9 \%)$ were the most commonly reported side effects in the 3 -week period of the acute mania study. ${ }^{19}$

There was no reported incidence of mania or hypomania reported in the acute depression study. However, two adverse events related to suicidal ideation/behavior were reported in the placebo arm and in one in the quetiapine arm. ${ }^{20}$ No incidence of new depression was reported in the acute mania study. ${ }^{19}$

\section{Extrapyramidal symptoms}

The use of quetiapine XR in bipolar disorder has been associated with extrapyramidal side effects. In the 3-week acute mania study, EPS, ie, akathesia, dystonia, hypertonia, tremors and extrapyramidal disorder, were reported in $4.4 \%$ of subjects compared to $0.7 \%$ in the placebo arm. ${ }^{19}$

\section{Body weight changes}

In a 3-week study of quetiapine XR in the treatment of bipolar mania, weight gain was noted to be relatively modest. ${ }^{17}$ Mean body weight changes were $1.3 \mathrm{~kg}$ for the quetiapine XR-treated patients and $0.1 \mathrm{~kg}$ for the placebo-treated patients. Body weight increase of $\geq 7 \%$ was reported in $5.1 \%$ of subjects receiving quetiapine XR compared to none in the placebo arm. In the 8-week acute bipolar depression study, the mean average weight gain for quetiapine was $1.3 \mathrm{~kg}$ compared to a $0.2 \mathrm{~kg}$ weight loss in the placebo arm. Body weight increase of $\geq 7 \%$ was reported in $8.2 \%$ of subjects receiving quetiapine XR compared to $0.8 \%$ in those receiving placebo. Long-term effect of quetiapine XR on weight gain in bipolar subjects has not been reported. Modest or moderate long term weight gain with quetiapine however has been reported with a mean average of $3.3 \mathrm{~kg}$ over a 12 -week period (mean dose of $618 \mathrm{mg}$ and range of 400 to $800 \mathrm{mg}$ daily). ${ }^{21}$

\section{Serum prolactin level}

Prolactin level changes were reported in the acute mania study. ${ }^{19}$ The mean prolactin level in the quetiapine XR arm ( $\mathrm{n}=126$ ) at baseline was $9.27 \mathrm{ng} / \mathrm{mL}$ compared to $8.28 \mathrm{ng} / \mathrm{mL}$ in the placebo arm $(n=145)$. At the end of the 3-week study, there was a mild increase in the quetiapine XR arm mean level to $10.02 \mathrm{ng} / \mathrm{ml}$ and relatively no change in the placebo $\operatorname{arm}(8.22 \mathrm{ng} / \mathrm{mL})$. No prolactin data were reported in the acute depression study.

\section{Metabolic risk factors}

In the acute mania study, Cutler and colleagues reported that $10.1 \%$ of subjects $(n=160)$ the placebo arms had a significant shift in blood pressure ( $\geq 130$ systolic or $\geq 85$ diastolic) compared to only $4.7 \%$ in the quetiapine XR $\operatorname{arm}(\mathrm{n}=151) .{ }^{19}$ However, the opposite was seen in fasting blood sugar where $4.1 \%$ of quetiapine XR treated subjects had a significantly high shift of fasting or random blood sugar $(\geq 5.55 \mathrm{mmol} / \mathrm{L})$ compared to only $1.6 \%$ in the placebo-treated cohort. Triglyceride changes were comparable between the two cohorts of the studies with less than $3 \%$ of subjects showing a shift in triglyceride levels to $\geq 1.7 \mathrm{mmol} / \mathrm{L}$. Only one subject in each arm had a significant decrease in high-density lipoprotein cholesterol to below normal levels. Similarly one subject in each group had a significant increase in waist circumference. The combined effect of these factors reflects that total percentage of patients with 3 or more factors for metabolic syndrome at the end of 3-week study was 12.5 in quetiapine XR arm and $12.6 \%$ in the placebo arm. ${ }^{19}$

By the end of the 8-week acute bipolar depression study, the results showed fairly similar side effects profiles, with $5.8 \%$ of quetiapine-treated subjects $(n=137)$ showing a significant increase in fasting glucose levels compared to $2.4 \%$ in the placebo-treated subjects $(n=141) .{ }^{20}$ Similarly, $5.18 \%$ of the quetiapine XR cohort had significant increase in cholesterol level compared to only $2.8 \%$ in the placebo arm. Triglyceride shifts to clinically significant ranges were seen in $8.3 \%$ and $7.5 \%$ of quetiapine XR and placebo subjects, respectively. ${ }^{20}$

\section{Conclusion}

Atypical antipsychotics have been increasingly used for the treatment of bipolar disorder. Recently presented data from two clinical trials in bipolar disorder patients demonstrated 
efficacy in the treatment of acute bipolar depression and acute mania. Adverse events of particular concern with quetiapine XR, similar to quetiapine IR, include somnolence, sedation, dizziness, EPS, weight gain and metabolic abnormalities.

\section{Expert opinion}

Efficacy between quetiapine XR and the immediate formatulation appear similar although there is no data on comparative efficacy of quetiapine XR versus quetiapine IR in patients with bipolar disorder. Möller et al reported comparable efficacy and adverse events profile between quetiapine IR twice per day and quetiapine XR once daily among subjects with schizophrenia. ${ }^{22}$ Quetiapine XR offers the benefit of once-daily dosage over quetiapine IR which is often dosed twice daily. Adverse effects with quetiapine XR do not generally appear vastly different from those reported in bipolar clinical trials with quetiapine IR. ${ }^{21,23-26}$

Though approved as an add-on to lithium or divalproex, there is no published study of quetiapine XR in bipolar patients as an add-on to either medication. However, combination therapy seems to be the rule rather than exception in treatment of bipolar disorder. In retrospective study of 2442 subjects enrolled in the Systematic Treatment Enhancement Program for Bipolar Disorder (STEP-BD) and who achieved full recovery for at least 8 consecutive weeks, the reported average number of prescribed psychotic medications was $2.05(\mathrm{SD}=1.11) .{ }^{27}$ The use of an atypical antipsychotic with a mood stabilizer is a common practice in inpatient as well as outpatient settings.

A comprehensive approach for the treatment of bipolar disorder calls for an early and accurate diagnosis, building a therapeutic alliance, psychotherapeutic intervention, proper monitoring and follow-up, and the proper selection of medication combinations. The last-named factor is influenced by demographic factors as well as past psychiatric and medical history and treatment of the patient and family members.

An important consideration, which has not been evaluated for quetiapine $\mathrm{XR}$, is its effects on treatment adherence in comparison to bipolar treatments that are dosed more than once daily. Dosage simplification measures, including reduction in daily dosing frequency, are known to improve treatment adherence in most psychiatric and medical populations. For example, a review by Claxton and colleagues across multiple disease states demonstrated an apparent relationship between adherence rates and dosing frequency with adherence of $79 \%$ for medications that required once-daily administration, 69\% for twice-daily dosing and 65\% for three-times-daily dosing. ${ }^{28}$ Studies are needed to address the clinically relevant question of whether quetiapine XR actually improves treatment adherence compared to quetiapine IR when it is dosed more than once daily.

\section{Five-year view}

The use of atypical antipsychotics in the treatment of bipolar disorder is a current standard of care. ${ }^{29}$ The role of atypical antipsychotics in the treatment of acute mania, acute bipolar depression and maintenance treatment is well established.

Quetiapine XR offers a longer-acting formulation with a potential role in maximizing adherence, but this needs a more focused assessment. Treatment nonadherence among subjects with bipolar disorder is estimated be around $40 \%$ and is associated with substantial humanitarian and financial burdens. ${ }^{30-32}$ While a once-daily treatment is likely to improve adherence for individuals who forget to take medication twice daily, formulations that require an even less frequent administration and perhaps with routes other than oral (ie, long-acting injectable compounds) such as once-weekly or once every 1 to 3 months should be a subject of future research focus.

\section{Disclosures}

Rayan K Al Jurdi, MD.

Grant/Research Funding: Cyberonics, Stanley Foundation, National Institute of Mental Health, Suicide Prevention Internationals, Mental Illness Research, Education and Clinical Center, Cephalon, American Foundation for Suicide Prevention, NARSAD, GlaxoSmithKline, Evotec, and Roche.

Lena A Dixit, BS.

No disclosure.

Martha Sajatovic, MD.

Research grants: GlaxoSmithKline, AstraZeneca; Consultant: AstraZeneca, GlaxoSmithKline, Cognition Group, United BioSource Corporation (UBC), ePharma Solutions; Royalties: Springer Press, Johns Hopkins University Press, Oxford Press.

\section{References}

1. Grant BF, Stinson FS, Hasin DS, et al. Prevalence, correlates, and comorbidity of bipolar I disorder and axis I and II disorders: results from the National Epidemiologic Survey on Alcohol and Related Conditions. J Clin Psychiatry. 2005;66:1205-1215.

2. Dinan TG. Lithium in bipolar mood disorder [editorial]. $B M J$. 2002;324:989-990.

3. Fountoulakis KN, Vieta E, Siamouli M, et al. Treatment of bipolar disorder: a complex treatment for a multi-faceted disorder. Ann Gen Psychiatry. 2007;6:27. 
4. Sajatovic M, Madhusoodanan S, Fuller MA, et al. Risperidone for bipolar disorders. Expert Rev Neurother. 2005;5:177-187.

5. Pope HG, McElroy SL, Keck PE, Hudson JI. Valproate in the treatment of acute mania: a placebo-controlled study. Arch Gen Psychiatry. 1991;48:62-68.

6. Bowden CL, Brugger AM, Swann AC. Efficacy of divalproex vs lithium and placebo in the treatment of mania. JAMA. 1994;271:918-924.

7. Goldsmith DR, Wagstaff AJ, Ibbotson T, Perry CM. Lamotrigine: a review of its use in bipolar disorder. Drugs. 2003;63:2029-2050.

8. McElroy SL, Keck PE. Pharmacologic agents for the treatment of acute bipolar mania. Biol Psychiatry. 2000;48:539-557.

9. Sajatovic M, Valenstein M, Blow FC, Ganoczy D, Ignacio RV. Treatment adherence with antipsychotic medications in bipolar disorder. Bipolar Disord. 2006;8(3):232-241.

10. Depp C, Ojeda VD, Mastin W, et al. Trends in use of antipsychotics and mood stabilizers among Medicaid beneficiaries with bipolar disorder, 2001-2004. Psychiatr Serv. 2008;59:1169-1174.

11. US FDA. Prescribing information. Seroquel XR (quetiapine fumarate) extended-release tablets [online]. Available from: http://www.accessdata fda.gov/drugsatfda_docs/label/2008/022047s006s007s0081bl.pdf. Accessed September 10, 2009.

12. US FDA. Prescribing information. Seroquel (quetiapine fumarate) tablets [online]. Available from: http://www.accessdata.fda.gov/ drugsatfda_docs/label/2008/020639s025s037s038s040lbl.pdf. Accessed September 10, 2009.

13. Jensen NH, Rodriguez RM, Caron MG, Wetsel WC, Rothman RB, Roth BL. N-desalkylquetiapine, a potent norepinephrine reuptake inhibitor and partial 5-HT1A agonist, as a putative mediator of quetiapine's antidepressant activity. Neuropsychopharmacology. 2008;33:2303-2312.

14. Altschuler EL, Kast RE. Using histamine (H1) antagonists, in particular atypical antipsychotics to treat anemia of chronic disease via interleukin-6 suppression. Med Hypoth. 2005;65:65-67.

15. Licinio J, Wong ML. The role of inflammatory mediators in the biology of major depression: central nervous system cytokines modulate the biological substrate of depressive symptoms, regulate stress-responsive systems, and contribute to neurotoxicity and neuroprotection. $\mathrm{Mol}$ Psychiatry. 1999;4:317-327.

16. Medicine evaluation board. Public assessment report of the medicines evaluation board in the Netherland [online]. Available from: http:// db.cbg-meb.nl/mri/par/nlh-0156-008-009-010-011.pdf. Accessed September 10, 2009.

17. Electronic Medicines Compendium. Seroquel Xl $50 \mathrm{mg}, 200 \mathrm{mg}$, $300 \mathrm{mg}, 400 \mathrm{mg}$ prolonged release tablets [online]. Available from: http://emc.medicines.org.uk/medicine/21175/SPC/Seroquel $\% 20 \mathrm{XL} \%$ $2050 \% 20 \mathrm{mg}, \% 20200 \% 20 \mathrm{mg}, \% 20300 \% 20 \mathrm{mg}, \% 20400 \% 20 \mathrm{mg} \%$ 20prolonged-release\%20tablets/. Accessed September 10, 2009.

18. Figueroa C, Brecher M, Hamer-Maansson JE, Winter H. Pharmacokinetic profiles of extended release quetiapine fumarate compared with quetiapine immediate release. Prog Neuropsychopharmacol Biol Psychiatry. 2009;33:199-204.
19. Cutler A, Datto C, Nordenhem A, et al. Effectiveness of the extended release formulation of quetiapine as monotherapy for the treatment of acute bipolar mania [poster]. Presented at the 8th Annual International Review of Bipolar Disorders Conference; April 14-16, 2008; Copenhagen Denmark.

20. Suppes T, Datto C, Minkwitz M, Nordenhem A, Walker C, Darko D. Effectiveness of the extended release formulation of quetiapine as monotherapy for the treatment of acute bipolar depression [poster]. Presented at the 8th Annual International Review of Bipolar Disorders Conference; April 14-16, 2008; Copenhagen Denmark.

21. Bowden CL, Grunze H, Mullen J, et al. A randomized, double-blind, placebo-controlled efficacy and safety study of quetiapine or lithium as monotherapy for mania in bipolar disorder. $J$ Clin Psychiatry. 2005;66:111-121.

22. Möller HJ, Johnson S, Mateva T, et al. Evaluation of the feasibility of switching from immediate release quetiapine to extended release quetiapine fumarate in stable outpatients with schizophrenia. Int Clin Psychopharmacol. 2008;23:95-105.

23. Calabrese JR, Keck PE, Macfadden W, et al. A randomized, double-blind, placebo-controlled trial of quetiapine in the treatment of bipolar I or II depression. Am J Psychiatry. 2005;162:1351-1360.

24. Thase ME, Macfadden W, Weisler RH, et al. Efficacy of quetiapine monotherapy in bipolar I and II depression: a double-blind, placebocontrolled study (The BOLDER II Study). J Clin Psychopharm. 2006;26:600-609.

25. Tohen M, Baker RW, Altshuler LL, et al. Olanzapine versus divalproex in the treatment of acute mania. Am J Psychiatry. 2002;159:1011-1017.

26. Yatham L, Paulsson B, Mullen J, Vagerö AM. Quetiapine versus placebo in combination with lithium or divalproex for the treatment of bipolar Mania. J Clin Psychopharm. 2004;24:599-606.

27. Al Jurdi RK, Marangell LB, Petersen NJ, Martinez M, Gyulai L, Sajatovic M. Prescription patterns of psychotropic medications in elderly compared with younger participants who achieved a "recovered" status in the systematic treatment enhancement program for bipolar disorder. Am J Geriatr Psychiatry. 2008;16:922-933.

28. Claxton AJ, Cramer J, Pierce C. A systematic review of the association between dose regimens and medication compliance. Clin Therap. 2001;23:1296-1310

29. Yatham LN, Kennedy SH, Schaffer A, et al. Canadian Network for Mood and Anxiety Treatments (CANMAT) and International Society for Bipolar Disorders (ISBD) collaborative update of CANMAT guidelines for the management of patients with bipolar disorder: update 2009. Bipolar Disord. 2009;11:225-255.

30. Sajatovic M, Valenstein M, Blow F, Ganozcy D, Ignacio R. Treatment adherence with lithium and anticonvulsant medications among patients with bipolar disorder. Psychiatric Services. 2007;58:855-863.

31. Perlick DA, Rosenheck RA, Kacynski R, et al. Medication nonadherence in bipolar disorder: a patient-centered review of research findings. Clinical Approaches in Bipolar Disorders. 2004;3:54-56.

32. Lingham R, Scott J. Treatment non-adherence in affective disorders. Acta Psychiatr Scand. 2002;150:164-172.
Neuropsychiatric Disease and Treatment

\section{Publish your work in this journal}

Neuropsychiatric Disease and Treatment is an international, peerreviewed journal of clinical therapeutics and pharmacology focusing on concise rapid reporting of clinical or pre-clinical studies on a range of neuropsychiatric and neurological disorders. This journal is indexed on PubMed Central, the 'PsycINFO' database and CAS, and is the official

\section{Dovepress}

journal of The International Neuropsychiatric Association (INA). The manuscript management system is completely online and includes a very quick and fair peer-review system, which is all easy to use. Visit http://www.dovepress.com/testimonials.php to read real quotes from published authors. 